Document downloaded from:

http://hdl.handle.net/10251/99222

This paper must be cited as:

Escrivá-Escrivá, G.; Segura Heras, I.; Alcázar-Ortega, M. (2010). Application of an energy management and control system to assess the potential of different control strategies in HVAC systems. Energy and Buildings. 42(11):2258-2267. doi:10.1016/j.enbuild.2010.07.023

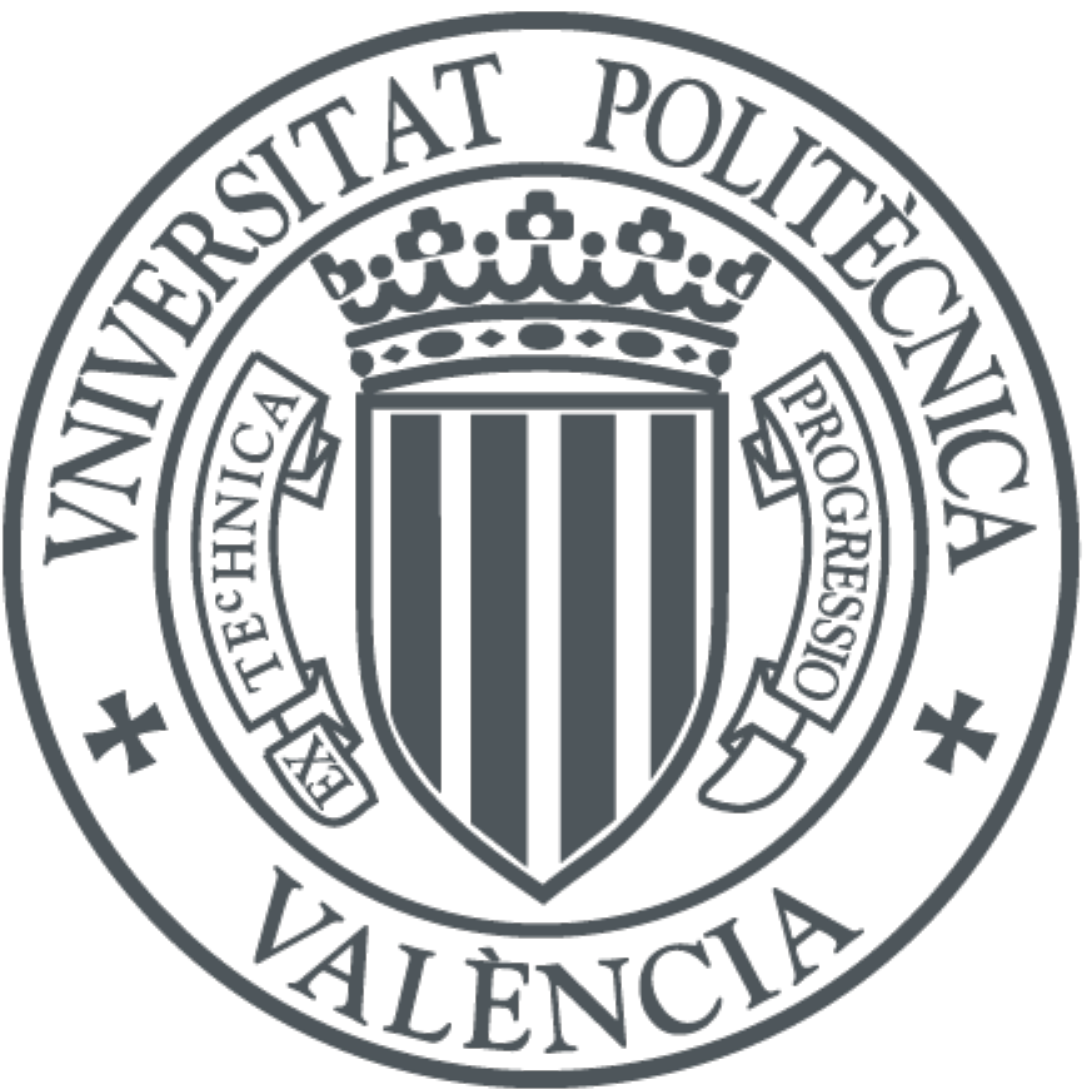

The final publication is available at

https://doi.org/10.1016/j.enbuild.2010.07.023

Copyright Elsevier

Additional Information 


\title{
APPLICATION OF AN ENERGY MANAGEMENT AND CONTROL SYSTEM \\ TO ASSESS THE POTENCIAL \\ OF DIFFERENT CONTROL STRATEGIES IN HVAC SYSTEMS
}

Guillermo Escrivá-Escrivá $\left({ }^{a}\right)$, Isidoro Segura-Heras $\left({ }^{a}\right)$, Manuel Alcázar-Ortega $\left({ }^{a}\right)$

(a) Institute for Energy Engineering, Universidad Politécnica de Valencia, Camino de Vera, s/n, edificio 8E, escalera F, $2^{\mathrm{a}}$ planta. 46022 Valencia, Spain

\begin{abstract}
The significant and continuous increment in the global electricity consumption is asking for energy saving strategies. Efficient control for heating, ventilation and air-conditioning systems (HVAC) is the most cost-effective way to minimize the use of energy in buildings. In this framework, an energy management and control system (EMCS) has been developed to schedule electricity end-uses in the campus of the Universidad Politécnica de Valencia (UPV), Spain.

This paper presents an evaluation performed by using the EMCS of different control strategies for HVAC split systems. It is analyzed the effect of different schedules for a common air-conditioning device and demand response strategies are tested in several situations. The economic saving is calculated taking into account the electricity contract clauses.

Finally, a test is made for the control of a group of similar devices in order to reduce the maximum peak power in consumption and to obtain a flexible load shape with the HVAC loads. The studies are then extrapolated to a larger system, the whole University campus, for which energy and economic savings are quantified.
\end{abstract}

Keywords: Energy saving strategies; energy management and control system; HVAC split system; demand response

\section{Introduction}

Nowadays, due to the requirements for the indoor air quality, the visual and thermal comfort levels have been increased [1, 2]. Heating, ventilation and air-conditioning systems (HVAC) 
represent an important share of the electricity consumption (about 30\%) in a building [3]. This implies that important energy and economic savings can be achieved by improving the efficiency in these systems, and therefore a substantial reduction in the environmental impacts can be also achieved [4]. There are several types of air-conditioning systems: the split and the centralized systems are the most usual configurations. An efficient use and control of these systems could result in important energy and economical savings without affecting the users comfort. Common centralized systems can be more efficiently managed, since they usually have an associated central control unit in which internal temperatures of several rooms and presence control devices are included [5-8]. Efficiency improvement actions are more difficult to implement for split systems because several units supply comfort to different areas and no centralized control system usually exists. Nevertheless, these split systems offer a large potential for savings.

About 1,500 HVAC split systems are spread out around the campus of the Universidad Politécnica de Valencia (UPV) [9] and they are being connected gradually to an energy management and control system (EMCS) [10]. Each device requires a skilful management to achieve an efficient operation.

Many studies have analyzed different control strategies for individual air-conditioning equipments [11-14]. This paper focuses on the evaluation of different control strategies that can be implemented in the developed ECMS for HVAC split devices installed in premises of the UPV developed in order to get an optimal strategy to apply throughout the whole University. Results of various tests are analysed. These tests focused on strategies that can be applied using the technology tools installed by means of the project DERD [10]. In particular, energy saving strategies of disconnection have been studied. A major impact on the University electric shape load is expected making possible for integration of the University in demand response programs in the future.

In section 2, the EMCS architecture and the objectives of the project for the University are introduced. Section 3 outlines the HVAC physical system studied including the characteristics of the site and the HVAC split device. The proposed methodology and the parameters of the test are presented in section 4 and 5 respectively. Afterwards, in section 6 and 7 savings and results are commented for different kinds of disconnection tests. An application is carried out for a 
group of devices working under a load displacement condition and an extrapolation to the whole University is set in section 8, including an evaluation of the flexibility obtained in the aggregated load shape and the corresponding energy and economic savings achieved. Finally some conclusions are summarized in section 9 .

\section{EMCS characteristics}

\subsection{Technological tools}

The goal of the developed DERD project is the implementation of new tools and techniques in order to facilitate the management of the different energy resources used in the existing infrastructures of the University, the improvement of the energy efficiency and the control of distributed loads.

These tools allow the facilities manager to measure energy consumptions, store and manage data, control energy consumptions and monitor that the power does not exceed a prefixed set point. In particular, most of the HVAC devices of the University are being connected to the EMCS and its consumption can be controlled by adjusting the timetable for the different loads and cases. The EMCS platform suits demand response programs [15, 16], including accurate metering, remote communication equipment by using TCP-IP protocol and software of control. All the information is gathered in the control center where the main server and the SQL database are located. The EMCS architecture is showed in Figure 1.

Figure 1. Architecture of the EMCS. 
All data can be reached through a web interface which facilitates access to the information from any point with Ethernet connection [10].

\subsection{Global objectives of the EMCS}

The development of this system provides an infrastructure with the ability to participate in electricity markets where disconnection of power could be offered as a service to the grid and facilitate the participation of customer in demand response programs. Furthermore, as the energy consumed by different facilities can be perfectly known, the electricity contract could be optimized, so that the electricity costs would be reduced. In this new framework, energy consumers could have an influence on the price and quantity of generated energy, so customers may offer energy not by producing it, but not consuming [17-19]. In this way, the system would allow demand response to be monitored by different agents, and price signals may be provided.

\subsection{Energy contract}

At the moment, the University has a six period electricity contract, which has a different price for each period from peak to valley. In this paper, the economic calculation has been done with those references for the year 2008. Tests of the HVAC devices were carried out during November and December working days.

Of course, the objective is to offset the electricity consumption by adjusting disconnections during peak periods and high electricity prices but without compromising comfort levels. In some cases, energy savings may be low, though the economic saving can be significant.

\section{Studied physical system}

\subsection{HVAC device description}

A specific HVAC system among the numerous HVAC split system installed in the University has been chosen in order to perform the tests. The device is an air-conditioning ducted-split system from Roca York. The exterior unit is the model AHO-200-B 38/B, horizontal device with an axial fan. The interior unit is the BCBI-20-2571 model. The electricity supply is a $400 \mathrm{~V}$, three phases, $50 \mathrm{~Hz}$ voltage. The cooling power is $22 \mathrm{~kW}$, the heating power is $23 \mathrm{~kW}$ and the coefficient of performance of heating is about 3.4 in nominal conditions. The stand-by power of 
the system is $70 \mathrm{~W}$ and the total nominal power of the device (compressor and fans) is about $7.75 \mathrm{~kW}$.

\subsection{Zone under evaluation}

The zone conditioned by the studied HVAC system is a part of the Electric Technologies Department of the University, on the second floor of the building. The area is $232 \mathrm{~m}^{2}$ and the zone is comprised of six offices and a little hall. The height is constant and equals to $2.92 \mathrm{~m}$. The external walls are: $73.3 \mathrm{~m}^{2}$ on the South West (SW) side, $47.7 \mathrm{~m}^{2}$ on the North West (NW) side, and $19.1 \mathrm{~m}^{2}$ on the South East (SE) side. The main materials are plaster, cement, concrete and EPS isolation materials with a thickness of $27 \mathrm{~cm}$. The windows represent a total surface of $38.6 \mathrm{~m}^{2}$ on the SW wall, $22.2 \mathrm{~m}^{2}$ on the NW wall, and $5 \mathrm{~m}^{2}$ on the SE wall. All the windows are metal framed and with transparent single glass. The total area of the internal walls is $157.4 \mathrm{~m}^{2}$. The walls are made of perforated bricks and plaster with a thickness of $18 \mathrm{~cm}$ each. The ceiling and floor have the same characteristics: paving and concrete with a thickness of 35 $\mathrm{cm}$. The predominant furniture is wood and it occupies the $10 \%$ of the total volume of the rooms. There is one fan in each office and two ones in the small hall.

\subsection{Test conditions}

The external doors and windows have to stay closed in the air-conditioned area in order to reduce electricity consumption and, overall, not to change the conditions for the different tests. This has a significant influence on the system. Moreover, it has been asked to the occupants of the area to keep all the windows closed, as a basic "green behavior".

Another important condition to validate the tests is to impose a constant set point temperature, so the cooperation of people who stay in the building is essential during the weeks when the tests are carried out. The selection of a comfort temperature is usually free and only depends on the users. By following the behavior of different occupants of the zone under evaluation, a temperature of $22^{\circ} \mathrm{C}$ is considered to be the comfort temperature for this area.

These two conditions, closed windows and constant set points, have been taken into account in order to get proper results. 


\subsection{Physical implementation of the actions}

The physical connections to do through the EMCS to implement the start/stop actions depend on the type of the controlled HVAC system. In Figure 2 it is shown two typical connections.
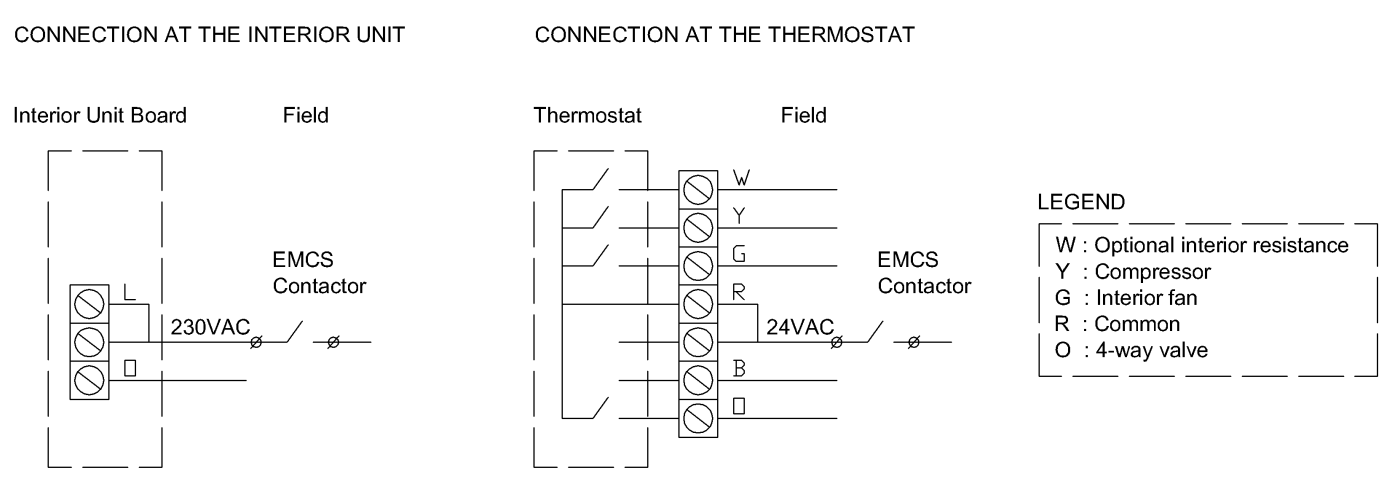

Figure 2. Physical connections.

Additionally, it is necessary to set the interior unit in auto-run mode, so when the EMCS contactor is closed the split turns on automatically.

This implementation makes possible either the end user controls the split system at its own will when the EMCS contactor is closed, or the shutdown of the split is forced by means of the EMCS when the contactor is opened.

Additionally, a temperature measuring probe has been placed in each site in order to maintain a comfortable internal temperature. In the event that there is a major difference between indoor temperature and the temperature for a certain threshold, the EMCS system overrides the control actions and reconnects the HVAC device.

\section{Methodology}

The methodology used for the evaluation of different control strategies is depicted in Figure 3. Firstly, the variables to consider in the test are defined (section 5). The next step is to perform the various tests, and then to analyze the obtained data. In order to get a proper conclusion from each test, it is necessary to appreciate if the environment variables remain or not in similar conditions between the "Test day", when the strategy is applied, and a "Reference day", considering a day in the same conditions, external and internal, as the "Test day" but without implementing any saving strategies. 


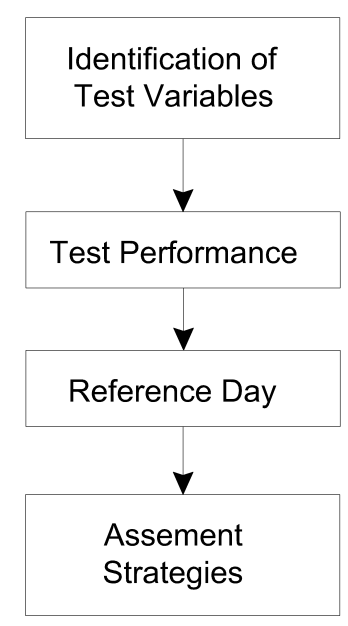

Figure 3. Proposed Methodology.

The behavior of certain parameters as the external temperature, humidity, schedules or occupancy, forms the main issue of an energy saving experiment and its evaluation. Therefore, the test is scheduled alternatively between a "Test day" and a day without any test: the most similar day is chosen to be the "Reference day", generally the following day or the previous day. Due to issues regarding to thermal inertia, the energy saving strategies are evaluated on working days except on Mondays: consumption on Mondays morning is larger than for the other working days because of the week-end break.

\section{Parameters of the tests}

Thanks to the communication equipment that is used in the EMCS, the data gathered during the test can be easily sent to the central control server. The parameters of the system to be considered in the developed test are presented below.

\subsection{States of the device}

Three different power levels of the device are possible:

- ON: The entire air-conditioning system device is working (i.e. compressor, fan, etc.).

- FAN: Only the interior fan is working.

- OFF: The electronic systems and the thermostat are on standby.

These states are measured to check the control of the machine and confirm if the device has permission to work or not, depending on the programmed and planned control. 


\subsection{Internal temperature (Tint)}

A temperature measuring probe has been placed in the site. The sensor is located at the center of the zone, in a proper air flow zone, and at an indicated height. The room has a certain thermal inertia and the temperature values are stored in a programmable logic controller, recorded every 15 minutes and then transmitted through the TCP-IP Ethernet Communication to the web platform.

\subsection{Exterior temperature (Text)}

The external temperature is measured by means of another sensor, installed on the top of the building. This variable does not change quickly. Characteristics of this sensor are similar to those of the room temperature one.

\subsection{Set temperature (Tc)}

The set temperature is the temperature of control, given by the thermostat. The device will be $\mathrm{ON}$ if it has permission to work and until the room temperature reaches the set temperature.

\subsection{Power consumption (Pot)}

A power meter has been installed to measure the corresponding power demand of the HVAC split system. The data is sent and stored in the central control center. The same action is performed for all the power meters connected to the EMCS in other buildings of the UPV. These meters can be configured by the EMCS with several acquisition intervals.

\subsection{Acquisition interval}

It is necessary to define an interval between two consumption measurements in order to show the machine working status (ON/OFF) and to represent the alternative series of nominal power and stand-by steps. For this reason, during the previous days to the tests, studies were performed for different duration intervals of $0.5,1,5,10$ and 15 minutes.

The total energy consumed between $t_{1}$ and $t_{2}$ is given by:

$W(t)=\int_{t_{1}}^{t_{2}} p(t) \cdot d t$

Using discrete data, this expression is calculated by expression (2) to obtain the energy consumed during a day. $P_{i}$ represents the instantaneous power at time $\mathrm{i} ; \mathrm{nm}$ is the acquisition interval expressed in minutes $(0.5,1,5,10$ or 15 minutes), and $n T$ is the total number of samples a long a day $(2.880,1.440,288,144$ or 96 respectively). 
$W=\sum_{1}^{n T}\left(\left(P_{i}+P_{i-1}\right) \cdot \frac{n m}{60 \cdot 2}\right)$

It was determined by the tests that 1 minute is an adequate interval for the study, that permits to get enough information to accurately represent the behaviour of the system, whose minimum variations are produced every 3 or 4 minutes. The mean squared error obtained during the tests was only $0.84 \%$ for the 1 minute intervals.

\section{Previous test results}

The department has been chosen as a test zone for the energy saving study because of its constant and similar occupancy during a working day, from 8 am to $9 \mathrm{pm}$. As a result, the internal loads are the same on the thermal balance of the system. Moreover, the various tests are performed in November and December, months in which the external conditions are quite constant in Valencia and the HVAC devices work on heat mode.

Before checking the control strategies for energy saving purposes, some evaluations of losses through windows and changes on the set points are done.

The results in terms of savings are introduced in the Table 1. The "Reference day" column groups the 24 hour consumption in kWh of the reference day, and the "Test day" column displays the consumption in kWh of the test day. The other two columns show the economic and energy savings percentages.

Table 1. Tests results.

\begin{tabular}{lcccc} 
Test & $\begin{array}{c}\text { Reference day } \\
(\mathrm{kWh})\end{array}$ & $\begin{array}{c}\text { Test day } \\
(\mathrm{kWh})\end{array}$ & $\begin{array}{c}\text { Energy saving } \\
(\%)\end{array}$ & $\begin{array}{c}\text { Economic saving } \\
(\%)\end{array}$ \\
\hline Forced Losses & 42.83 & 62.39 & -45.67 & -45.53 \\
Tc $=23^{\circ} \mathrm{C}$ & 42.23 & 58.55 & -38.65 & -45.30 \\
Tc $=21^{\circ} \mathrm{C}$ & 68.95 & 42.38 & 38.54 & 39.16 \\
Test 1 & 46.76 & 45.39 & 2.93 & 5.05 \\
Test 2 & 44.02 & 41.53 & 5.66 & 6.37 \\
Test 3 & 43.95 & 41.98 & 4.48 & 5.45 \\
Test 4 & 44.15 & 39.21 & 11.19 & 8.78 \\
Test 5 & 43.92 & 48.85 & -11.22 & -13.91 \\
Test 6 & 43.18 & 56.82 & -31.59 & -1.18 \\
Test 7 & 46.76 & 45.48 & 2.74 & 8.36 \\
Test 8 & 43.09 & 34.34 & 20.31 & 19.40 \\
Test 9 & 43.83 & 40.52 & 7.55 & 17.62 \\
Test 10 & 44.79 & 41.44 & 7.48 & 21.11 \\
Test 11 & 66.32 & 53.84 & 18.82 & 19.25
\end{tabular}




\subsection{Forced energy losses}

The objective is to quantify how the electrical consumption increases in conditions of unnecessary losses. The test is performed leaving opened a window on the NW side of the department. The area of the window is $1.80 \mathrm{~m} \times 1.00 \mathrm{~m}(1.5 \%$ vertical surface of the total external walls). In this case, from the initial moment at 8am, it is observed that the temperature of the room strongly depends on the external temperature while the window stays open, until $2 \mathrm{pm}$. Since 8am, the HVAC system is working constantly at nominal power, reaching finally the set temperature at 2:30pm, so 30 minutes after the window was closed and never before this closing was done.

\subsection{Increment and decrement of $1^{\circ} \mathrm{C}$ of the set point}

Changing the set temperature has a direct influence on the behavior of the device, by the modification of the morning peak duration and duty cycle value.

The morning peak defines the energy consumed to raise the temperature from the lowest temperature (at 7:59am, after a night with neither activity nor space heating, and before switching on the HVAC system) to the set temperature: its duration is directly linked with the set temperature.

During the rest of the day, the HVAC demand matches the set temperature and external temperature influences. At the moment of higher temperature at midday, the demand is lower, but it increases during the afternoon following the fall of the temperature up to night time. Of course, the number of power step responses and duty cycle rise with the set temperature configuration.

As it is shown in Table 1, set point temperature is very important and affects in the energy consumption by more than $40 \%$.

\section{Control strategies}

The tools implemented in the EMCS make possible the reschedule of the start/stop times of the HVAC system, which is especially useful for weekends and nights. Since it has been implemented at the UPV campus, the EMCS has been used for switching off HVAC systems when they were not necessary, for instance, at night from 9pm-10pm to 6am-8am. 
In order to achieve an efficient operation in the analyzed system, the study depicted in this paper proposes the disconnection of devices during part of the day, so energy and economic savings can make attractive the implementation of these additional strategies. Different possibilities of disconnection are considered and introduced in the next sections and results have been presented in Table 1.

\subsection{Interruption during the warmest period of the day}

In winter, the temperature reaches its maximum daily value at midday, especially in sunny days. Generally, the demand of HVAC devices follows the external temperature and, at this moment, its consumption is lower. Taking into account this consideration, switching off the device during a short period of time should not modify a lot the room temperature.

- $\quad$ Test 1: Switching off during 1 hour (from $12 \mathrm{pm}$ to $1 \mathrm{pm}$ ). The user does not feel any change since the internal temperature falls only by $0.10^{\circ} \mathrm{C}$ from the set point.

- $\quad$ Test 2: Switching off during 3 hours (from $12 \mathrm{pm}$ to $3 \mathrm{pm}$ ). Due to the thermal inertia of the building, the quite high external temperature and the thermal effect of other loads (i.e. lighting, computers and occupants), the internal temperature does not change too much $\left(-0.20^{\circ} \mathrm{C}\right)$, as shown in Figure 4.

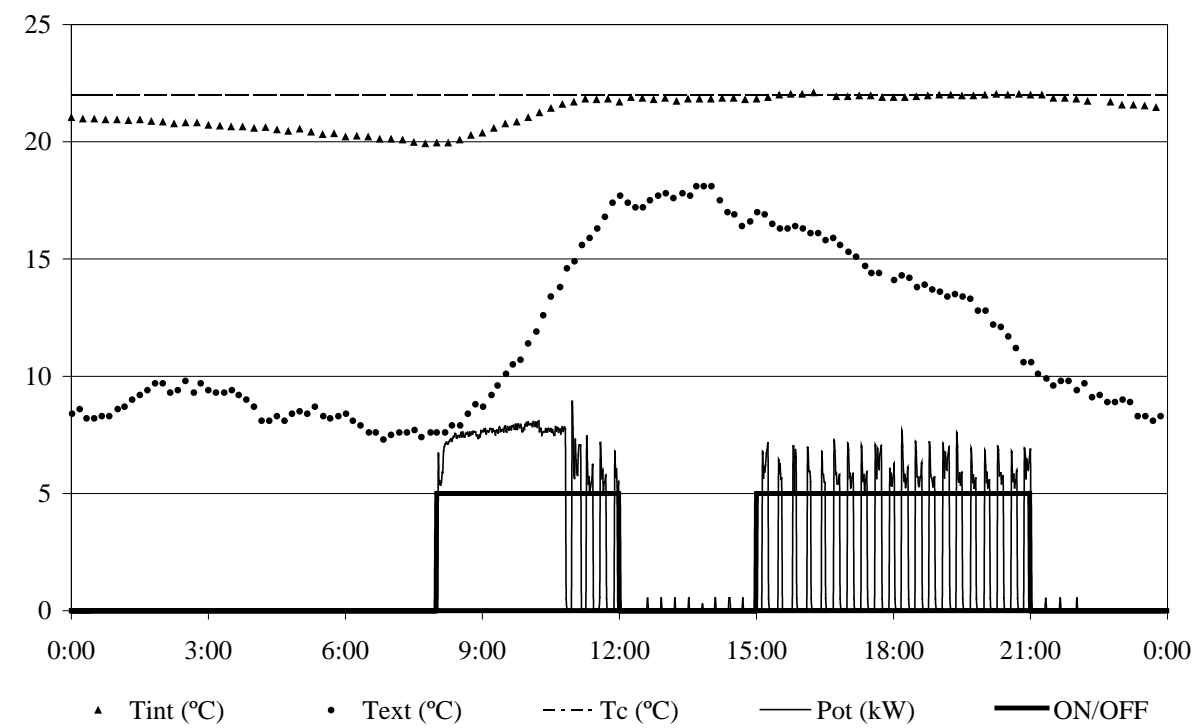

Figure 4. Test 2: Switching off during 3 hours (from 12pm to $3 p m$ ).

Additionally, these periods correspond to the lunch time, so no large disturbances are produced to the users. 


\subsection{Switching off time optimization}

The HVAC device is normally working from 8am to 9pm. Meanwhile, as users answered in a survey, the working period takes place from 9am to $9 \mathrm{pm}$. Consequently, the device does not require remaining connected until the end of the working period, in order to get benefits from the thermal inertia of the building [7].

- Test 3: Switching off 1 hour in advance (at 8pm). At 9pm the internal temperature was $21.73^{\circ} \mathrm{C}$.

- Test 4: Switching off 2 hours in advance (at $7 \mathrm{pm}$ ). At $9 \mathrm{pm}$ the internal temperature was $21.57^{\circ} \mathrm{C}$, value not far from the comfort set point of $22^{\circ} \mathrm{C}$, as shown in Figure 5 .

Disconnecting HVAC devices in advance provides good results. The economic savings are significant due to the high price of electricity at that time. This strategy can be extended to other devices, although times should be adapted to the specific requirements of each zone.

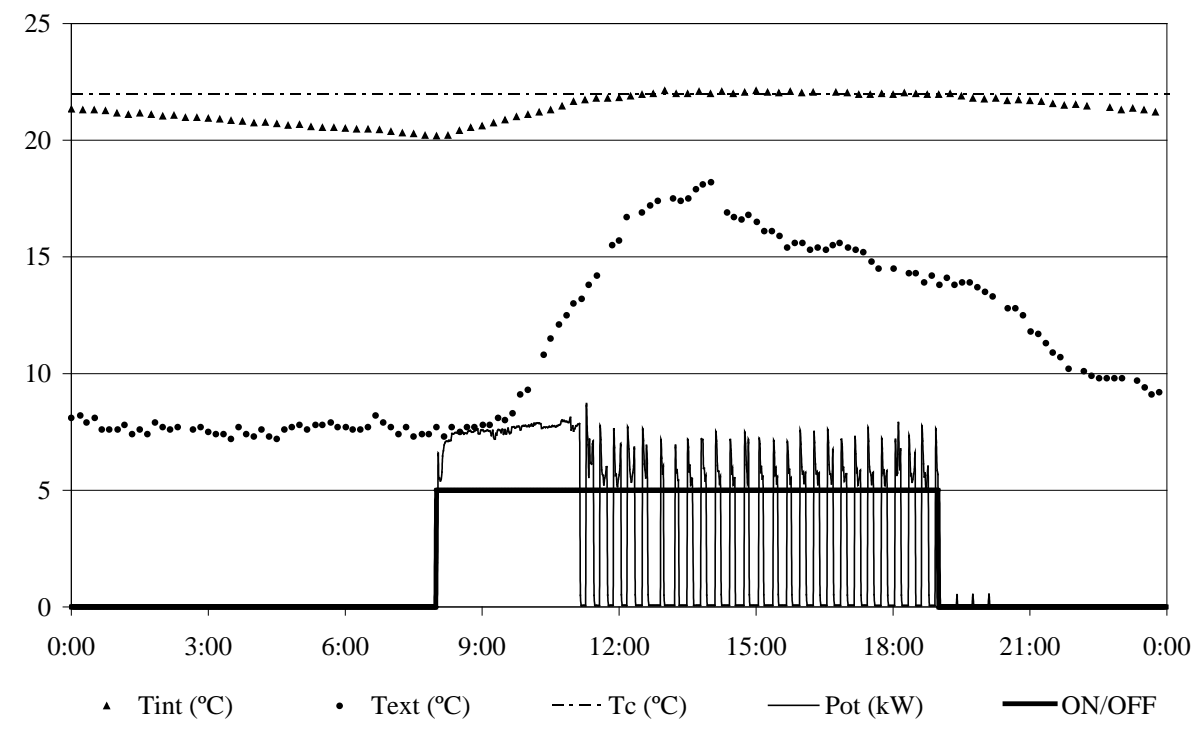

Figure 5. Test 4: Switching off 2 hours before (at $7 \mathrm{pm}$ ).

\subsection{Pre-heating during off-peak hours}

Switching off the surplus of a significant number of HVAC devices during the night by the EMCS (from 9pm-10pm to 6am-8am) increases the global morning peak of the whole campus. In a working day, as the devices use to start at $8 \mathrm{am}$, the comfort temperature is not reached up to the end of the morning peak when electricity prices are the highest. For that reason it is proposed to displace part of the consumption to cheaper periods, by means of a pre-heating of buildings during off-peak hours. 
- Test 5: Pre-heating during one hour (from 7am to 8am), and stop (from 8am to 9am). This strategy is not profitable because the pre-heating is too short.

- Test 6: Pre-heating during three hours (from 5am to 8am), and stop (from 8am to 9am). At 8am, the internal temperature almost reaches the set point temperature because the pre-heating period duration is quite similar to the morning peak of the "Reference day". The internal temperature decreases a bit (from 8am to 9am), but from 9am to 10:40am the device demand the nominal power until the set temperature is reached. So, although the widest power jump takes place when the energy is cheaper, the energy consumption is too elevated.

- Test 7: Pre-heating during two hours (from 6am to 8am), and stop (from 8am to 9am and from $2 \mathrm{pm}$ to $3 \mathrm{pm})$. At 9am, the temperature of the room does not decrease up to the initial value it had at $6 \mathrm{am}$, a part of the supplied heat is not lost. The internal temperature is $21.20^{\circ} \mathrm{C}$, which can be considered as a proper comfort temperature. Switching off from $2 \mathrm{pm}$ to $3 \mathrm{pm}$ makes the machine work during the same number of hours as the reference day, without disturbing the users, as shown in Figure 6.

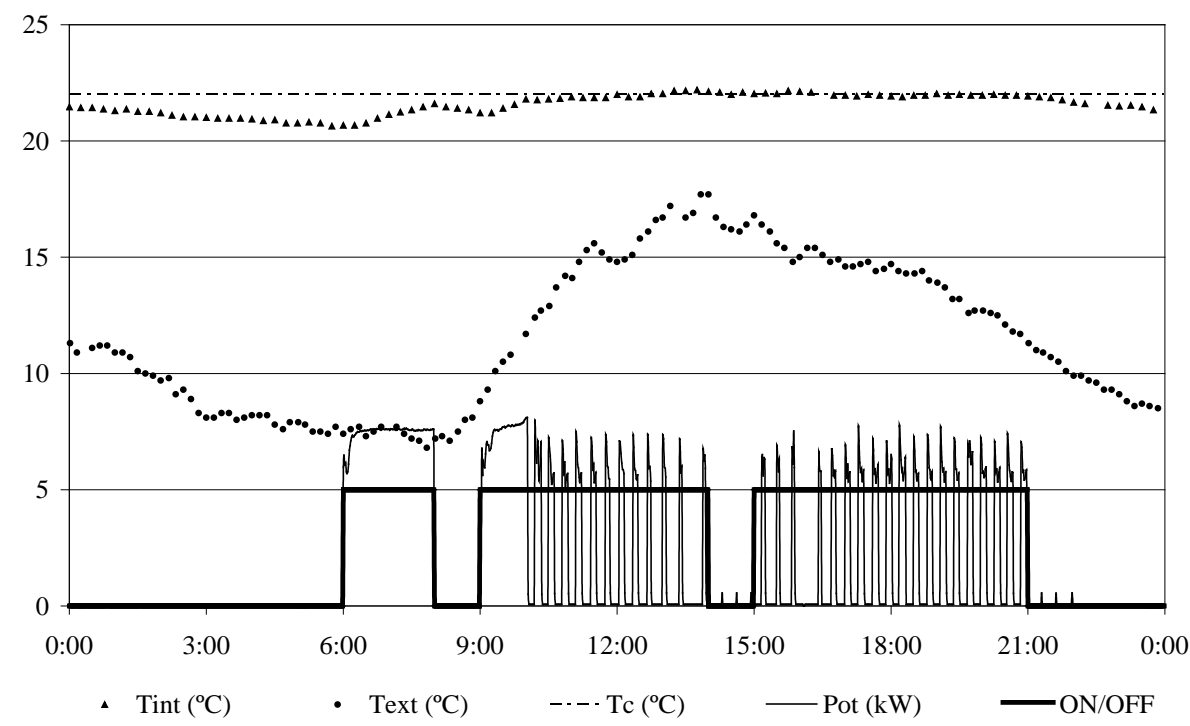

Figure 6. Test 7: Pre-heating during two hours (from 6am to 8am), and stopping (from 8am to 9am and from $2 \mathrm{pm}$ to $3 \mathrm{pm})$.

Switching on the device before 8am in order to warm up the room during a period in which the electricity is cheaper is a correct way to save money and displace the electric load, while energy is stored in the room. The pre-heating period must be shorter than the reference 
morning peak but not too short, in order to reduce loses since the pre-heating occurs when the external temperature is the daily lowest.

\subsection{Alternative on and off operating modes}

Another way to save energy and money by using a HVAC operation time schedule can be to toggle on and off the device during the working period.

- Test 8: Alternative on and off operating modes with duration of 1 hour. The test is based on switching on and switching off the HVAC system alternatively every hour, from 7 am to $9 \mathrm{pm}$ (one hour on, the next hour off, etc.). Consequently, there are 8 intervals of one hour during that the device is working. The energy and economic savings are significant (Table 1). Nevertheless, the internal temperature only reaches the set point at 12pm, although the device began working at $7 \mathrm{am}$. Therefore, the comfort level of users decreases during the morning.

- Test 9: Alternative on and off operating modes with duration of $1 / 2$ hour and pre-heating. The test is based on switching on and switching off the HVAC system every half an hour up to $9 \mathrm{pm}$ (Figure 7). Therefore, there are 11 intervals of half an hour each. In order to increase the comfort level during the morning, pre-heating during two hours is done from $6 a m$ to $8 a m$. The system stops for an hour from 8am to 9am, and then, it is switched on again from 9am to $10 \mathrm{am}$. The internal temperature stays comfortable during the whole working period.

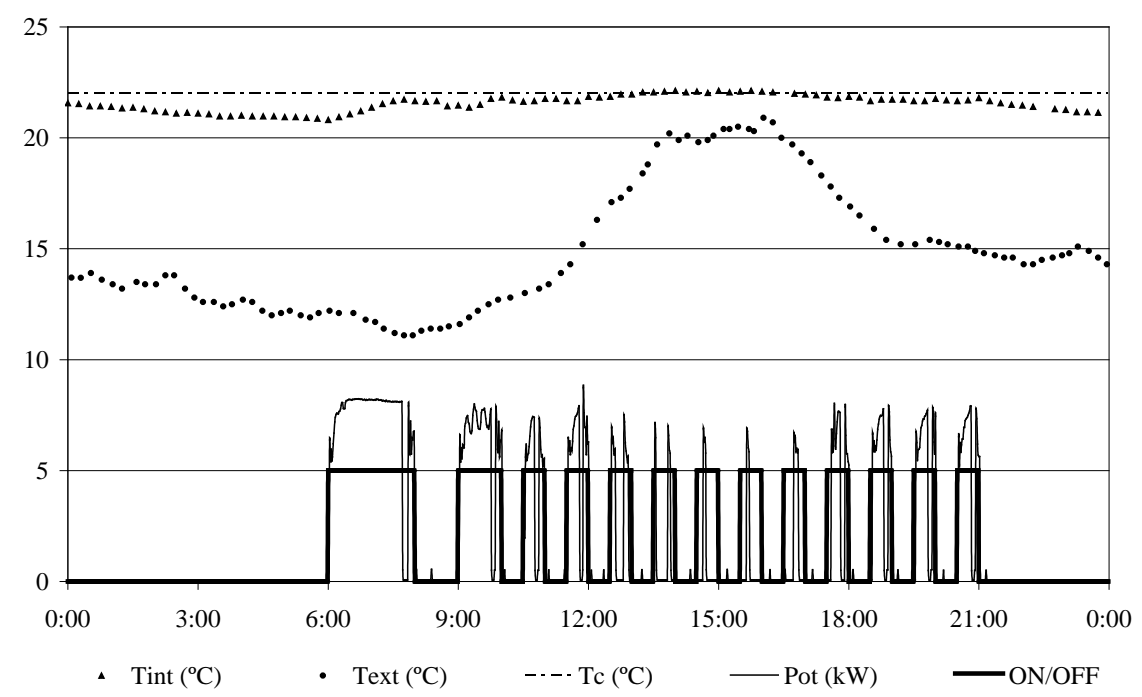

Figure 7. Test 9: Alternative on and off operating modes with duration of $1 / 2$ hour and preheating. 
For a wide range of devices, the necessary number of actions to be programmed by the EMCS can be an inconvenience to apply this control. Therefore, an alternative switching on and switching off operation is profitable, but internal temperature must be taken into account especially during the morning, when heating is more substantial.

\subsection{Combined controls}

Different tests have been presented. However, none of them shows a completely satisfactory result. Tests 7 and 9 could be probably considered as the most attractive ones. Nevertheless, the combination of several control strategies seems to be the best option in order to achieve significant energy reductions with low temperature degradation.

- Test 10: Pre-heating during off-peak period (from 5am to 8am), switching off at midday (from $12 \mathrm{pm}$ to $3 \mathrm{pm}$ ), and switching off two hours in advance (at $7 \mathrm{pm}$ ). In this test, the device works two hours less than in the "Reference day". The room accumulates energy during the morning, and its temperature remains on the acceptable threshold of comfort during the whole day $\left(21.53^{\circ} \mathrm{C}\right.$ at $\left.9 \mathrm{pm}\right)$. The economic savings are significant because the morning peak consumption is moved to a lower price period.

- Test 11: Pre-heating during off-peak period (from 6am to 8am), switching off at midday (from $1 \mathrm{pm}$ to $3 \mathrm{pm}$ ), and switching off one hour in advance (at $8 \mathrm{pm}$ ). The combination of the same strategies as above but in a less aggressive way, with shorter off periods, makes energy savings be significant. The internal temperature is really close to the set temperature during the whole day (Figure 8). 


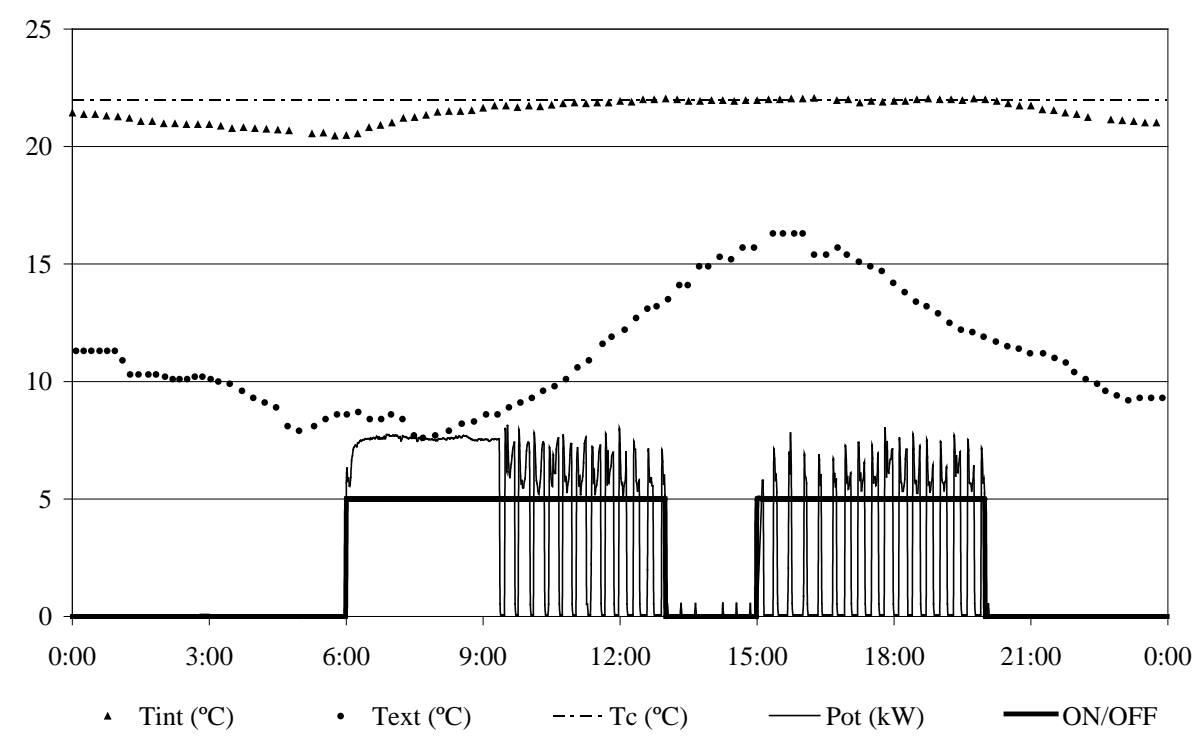

Figure 8. Test 11: Pre-heating during off-peak period (from 6am to 8am), switching off at midday (from $1 \mathrm{pm}$ to $3 \mathrm{pm}$ ), and switching off one hours in advance (at $8 \mathrm{pm}$ ).

Therefore, a combination of such actions as pre-heating during off-peak periods, switching off at midday, and switching off in advance in the evenings seems to be the best energy saving strategy. That makes possible to take advantage of low prices in the first hours in the morning, warm periods at midday and thermal inertia of buildings in the evening.

Furthermore, these combined controls are the most interesting ones to implement through the EMCS in the whole campus, always paying attention to the duration of the actions according to each situation. This control does not need too many actions and the switch-off intervals can be configured with respect to the physical zone needs, with the collaboration of the users.

It is significant to denote that the duration of the actions might vary depending on the time of the year, the external temperature, and the physical characteristics of the each zone. It is possible to store in the database of the EMCS all the data for each controlled split system, so the actions can be performed each time following the corresponding timetable.

\section{Extrapolation to the whole campus}

As a previous study to the extrapolation of the results to the whole campus, a test has been conducted to implement the deduced control strategies in a group of seven splits HVAC systems, similar to the device in the previous study. 


\subsection{Load displacement of a group of similar HVAC split systems}

Seven similar devices in the same building have been controlled for this test. In the case of applying the same switch-off strategy as the "Reference day" (from 8am to 9pm), the simultaneous start of the seven systems would produce notable morning peaks. The purpose of this study is to show the variation of the aggregated daily load curve thanks to a switch-off distributed planning of the devices. In the test, three devices were programmed at 6am whereas the other four started at $7 \mathrm{am}$, in order to displace the morning peak.

Each device stops for two or three intervals of one hour between 9am to $4 \mathrm{pm}$. The internal temperature remains clearly between the comfort limits. Figure 9 shows that the daily aggregated load curve of the test is flatter than the reference curve, which is very satisfactory. The morning peak goes through a 30\% reduction and the economic savings are about $5.3 \%$.

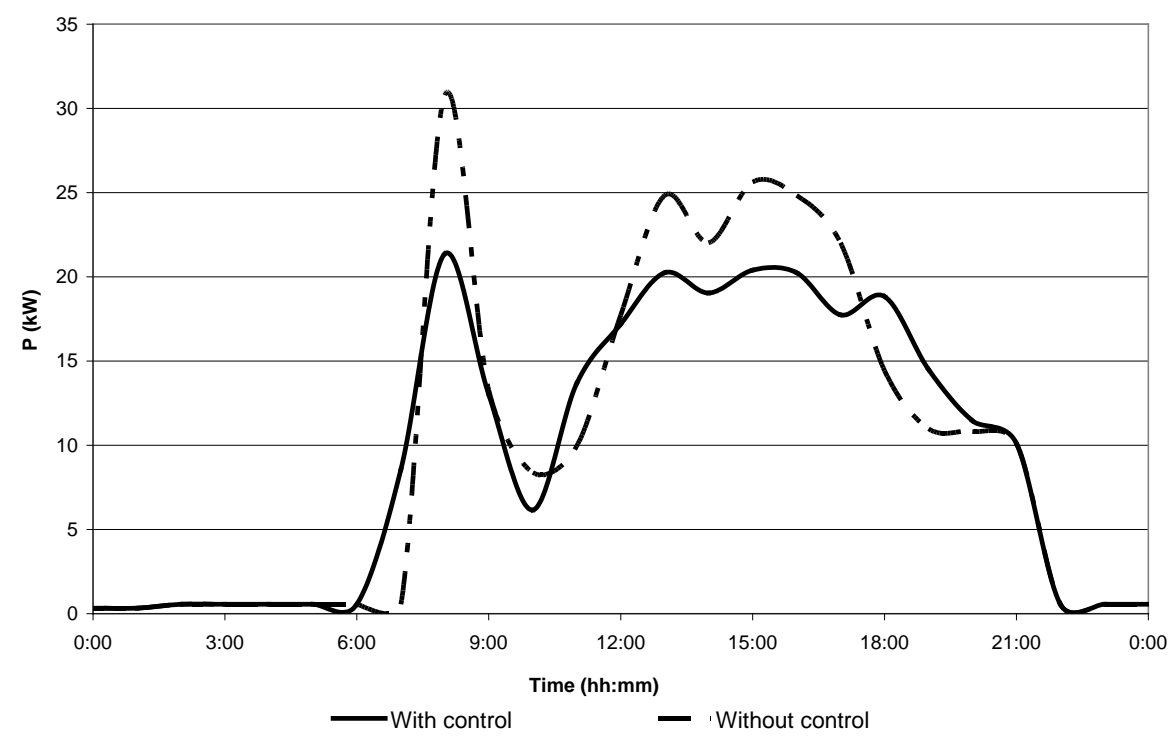

Figure 9. Load displacement of seven HVAC split systems.

\subsection{Extrapolation to the whole University}

In order to analyze the savings that could be achieved for the whole campus through the proposed control strategies, the flexibility of the HVAC systems should be evaluated. A meter has been installed to measure the total consumption of the campus. As expected, the global load of the University depends strongly on the external temperature, so consumption for the warmest and coldest days (located in July and January respectively) is very high.

Estimations indicate that about 1,500 devices will be connected to the EMCS once the DERD system is completely installed in the whole campus. However, some of the devices do 
not have any flexibility. This is the case of the air-conditioning in laboratories, computing rooms or departments of metrology, where the temperature of the room must be constant.

Taking into account the total load of the whole University for different periods of the year, an evaluation of the end-uses which directly depends on the external temperature may be done. For this significant part of the total load, about $2 \mathrm{MW}$ are considered neither controlled nor disconnected during nights (Figure 10).

As the ratio between the HVAC load and the rest of loads in the buildings controlled by the EMCS is known, it is possible to extrapolate such ratio to the whole campus in order to determine the total value of HVAC power to be controlled.

With these results, a simulation has been done in order to extrapolate disconnections strategies to the University. Each device controlled by the EMCS is disconnected during the night and additional disconnections are distributed during the day. Disconnections are not uniformly distributed, but especially oriented to displace the load, as studied in the previous tests. Devices are switched off for one or two hours, that is considered acceptable in terms of comfort.

The results of the simulation are shown in Figure 10. The University consumption and the daily aggregated HVAC load curves are presented with and without control for a particular day, December $17^{\text {th }}$ 2008. It is observed that most of the devices start gradually before the normal schedule. As a consequence, the morning peak is displaced and the University load peak lightly decreases.

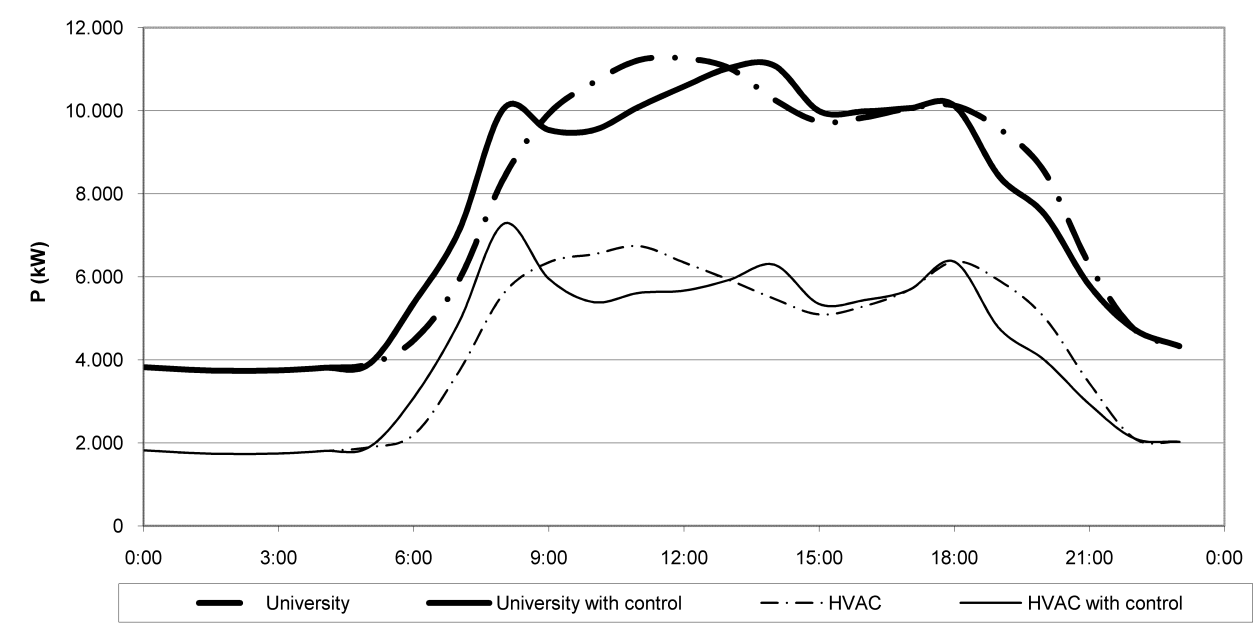

Figure 10. Extrapolation to the whole University. 
Moreover, disconnections are distributed along the day in order to flatten the load curve. Therefore, most of the devices are disconnected in advance in order to take advantage of the thermal inertia before the night. Table 2 shows the result of the extrapolation for this day. The displacement of the load is responsible of significant savings, especially because of the consumption during lower price periods.

Table 2. Extrapolation results to total University consumption.

\begin{tabular}{lcccc} 
& \multicolumn{2}{c}{ HVAC } & \multicolumn{2}{c}{ University } \\
\cline { 2 - 5 } & With control & Without control & With control & Without control \\
\hline Max Power (kW) & 7,282 & 6,739 & 11,093 & 11,268 \\
Average Power (kW) & 4,150 & 4,193 & 7,423 & 7,467 \\
Energy (kWh) & 99,588 & 100,635 & 178,159 & 179,206 \\
Cost (€) & 11,621 & 11,955 & 20,708 & 21,041 \\
Energy savings (kWh) & & \multicolumn{2}{c}{1,046} & \\
Economic savings $(€)$ & \multicolumn{3}{c}{334}
\end{tabular}

\section{Conclusions}

In the framework of the current energy markets, where prices are growing and the influence of the demand side is more and more important, it is essential to avoid wasting energy. Sometimes, very basic and easy-to-implement actions can really reduce the environmental impact of the use of energy. For instance, closing the windows or adjusting the set point temperature of a HVAC device represents an important reduction of the energy consumption.

UPV has developed the DERD project in order to use demand response tools for saving energy as much as possible in its campus facilities, without producing an appreciable impact in the comfort level. In particular, all the HVAC systems will be controlled by a central EMCS, by using a specific schedule for each device connected to the system. The obtained results of the implemented control strategies show a high potential of this tool in order to get important peak reductions and the subsequent economic benefits. This is achieved by using a combination of such actions as pre-heating during off-peak periods, switching off at midday, and switching off in advance in the evenings. That makes possible to take advantage of low prices in the first hours in the morning, warm periods at midday and thermal inertia of buildings in the evening. At the same time, the comfort level in the room is maintained. However, the application of these 
strategies should be done very carefully, taking into account weather conditions, physical characteristics and the evolution of internal temperatures of each zone. The information about the specific duration of each action can be stored in the database of the EMCS for the different situations.

An extrapolation of these techniques has been completed and promising saving in energy and costs are deduced. Works to finish the implementation of the system are now in progress in the whole campus and a further study will be done with the final situation.

\section{Acknowledgement}

This research work has been possible with the support of the Universidad Politécnica de Valencia (Spain) by the grant \#CE 19990032.

\section{References}

[1] D. Kolokotsa, D. Tsiavos, G. S. Stavrakakis, K. Kalaitzakis, E. Antonidakis. Advanced fuzzy logic controllers design and evaluation for buildings' occupants thermal-visual comfort and indoor air quality satisfaction. Energy and Buildings, Vol. 33, No. 6, pp. 531-543, July 2001 [2] ASHRAE (1999). Ventilation for Acceptable Indoor Air Quality, Standard 62-1999. American Society for Heating, Refrigerating and Air-Conditioning Engineers, Atlanta, GA.

[3] M. W. Ellis, E. H. Mathews. Needs and trends in building and HVAC system design tools. Building and environment, No. 37, pp. 461-470, 2002.

[4] D. W. Aitken, S. T. Bull, L. L. Billmann. The climate stabilization challenge: can renewable energy sources meet the target?. Renewable energy world, No. 7, November 2004 [5] Tianzhen Hong, S.K. Chou, T.Y. Bong. Building simulation: an overview of developments and information sources. Building and environment, No. 35, pp. 347-361, 2000.

[6] W. Kastner, G. Neugschwandtner, S. Soucek, H. M. Newman. Communication systems for building automation and control. Proceedings of the IEEE, No. 6, Vol. 93, June 2005.

[7] G. Escrivá, C. Álvarez, I. Valencia. Method for modelling space conditioning aggregated daily load curves: Application to a univertity building. Energy and Buildings (42) (2010) 12751282. 
[8] C. Selcuk Canbay, A. Hepbasli, G. Gokcen. Evaluating performance indices of a shopping centre and implementing HVAC control principles to minimize energy usage. Energy and buildings, No. 36, pp. 587-598, 2004.

[9] Maintenance service, Universidad Politécnica de Valencia. Inventario de equipos e instalaciones, 2009

[10] G. Escrivá, M. Alcázar, C. Álvarez. Integral Management System for the energy efficiency improvement in commercial facilities: Application to the Polytechnic University of Valencia. International Conference on Renewable Energies and Power Quality, April 2009.

[11] M. Ilic, J. W. Black and J. L. Watz. Potential benefits of implementing load control. Proceedings IEEE power engineering society winter meeting, Vol. 1, pp 177-182, New York, January 2002.

[12] A. Molina, A. Gabaldón, M. Kessler, J.A. Fuentes. Application of smoothing techniques to solve the cooling and heating residential load aggregation problem. Proc. VII Int. Conf. Probabilistic Methods Appl. Power Syst., Vol. 2, pp. 879-886, Sept. 2002.

[13] C. Alvarez, R.P. Malhamé and A. Gabaldón. A class of models for load management application and evolution revisited. IEEE Trans. Power Syst., No. 7, (4), pp. 1435-1443, 1992. [14] M. Anderson, M. Buehner, P. Young, D. Hittle, C. Anderson, J. Tu, D. Hodgson. An experimental system for advanced heating, ventilating and air-conditioning (HVAC) control. Energy and building, No. 39, pp. 136-147, 2007.

[15] C. Álvarez, A. Gabaldón and A. Molina. Assessment and simulation of the responsive demand potential in end user facilities: application to a University customer. IEE proceedings on gener. transm. and distribution, Vol. 150, pp. 61-66, January 2003.

[16] D. S. Kirschen. Demand-side view of electricity markets. IEEE Trans. Power Systems, vol. 18, No. 2, pp. 520 -527, May 2003.

[17] G. C. Heffner. Configuring load as a resource for competitive electricity, markets - Review of demand response programs in the U.S., and around the world. Environmental Energy Technologies Division, Ernest Orlando Lawrence Berkeley National Laboratory, University of California, Berkeley, California 94720, November 2002.

[18] International Energy Agency. The power to choose. Demand Response In Liberalised Markets. IEA publications, 2003. 
[19] Kathleen Spees, Lester B. Lave. Demand Response and Electricity Market Efficiency. The Electricity Journal, Vol. 20, No. 3, pp. 69-85, April 2007 